DOI 10.5216/ia.v45i3.65076

\title{
A OFERTA DE DISCIPLINAS DA ÁREA DE CIÊNCIAS SOCIAIS EM CURSOS DE BACHARELADO DE UMA UNIVERSIDADE PÚBLICA
}

\author{
Orcione Aparecida Vieira Pereira \\ Universidade do Estado de Minas Gerais (UEMG), Ubá, Minas Gerais, Brasil
}

\begin{abstract}
Resumo: Este artigo verifica como as disciplinas de Antropologia, Ciência Política e Sociologia, que são as principais áreas das Ciências Sociais, estão sendo ofertadas em cursos de graduação na modalidade bacharelado. Trata-se de uma pesquisa descritiva documental. Foram identificados 61 cursos de bacharelado presenciais ofertados em uma universidade pública do estado de Minas Gerais. Destes, 41 cursos ofereciam 161 disciplinas da área de Ciências Sociais e, entre essas disciplinas, $72,0 \%$ eram obrigatórias e $78,4 \%$ ministradas nos períodos iniciais. Constatou-se que os cursos de graduação de diversos campos do saber ofertavam pelo menos uma disciplina da área de Ciências Sociais, o que mostra a inserção dessas disciplinas e a possibilidade de contribuição de suas diferentes teorias e metodologias para a formação dos graduandos.

Palavras-chave: Ensino de Ciências Sociais. Graduação. Currículo. Projetos Pedagógicos de Cursos.
\end{abstract}

\section{INTRODUÇÃO}

Poucos estudos no Brasil abordam algum aspecto que constitui a análise do ensino de Antropologia, Ciência Política e/ou Sociologia em cursos de graduação (SARTORI, 2012; AMARAL, 2014; MARTINS, 2017; ANDRADE, 2018; SANTOS, 2018; SARMENTO; REZENDE; SANTOS JÚNIOR, 2019; FURLIN, 2020). Os autores, de uma forma geral, salientam que há muitas pesquisas sobre o ensino de Sociologia na Educação Básica, mas ainda há pouca literatura nacional sobre o ensino dessas disciplinas na graduação.

No ano de 2018, no país, eram ofertados 37.962 cursos de graduação presenciais e a distância que se dividiam nas modalidades bacharelado $(n=22.737)$, licenciatura $(n=7.415)$ e tecnólogos $(n=7.810)$, os quais tinham 8.450 .755 alunos matriculados. Destes, 5.689.335 estavam matriculados nos cursos de bacharelado. Em relação à distribuição dos cursos de graduação presenciais por área do saber, destacamse os cursos na área de Negócios, Administração e Direito $(n=8.245)$, de Engenharia, Produção e Construção $(n=5.870)$ e os da área de Saúde e Bem-Estar ( $n=5.499)$, entre outros (INEP, 2019). Esses dados evidenciam a importância de pesquisar como as atividades no âmbito da graduação estão sendo desenvolvidas.

Após ministrar por vários anos disciplinas da área de Ciências Sociais em cursos de graduação presenciais de várias áreas do conhecimento, questiona-se: como o ensino 
de Sociologia e de outras disciplinas que compõem as Ciências Sociais, tais como a Antropologia e a Ciência Política, está sendo desenvolvido nesses cursos? De que forma essas disciplinas estão previstas e situadas nos projetos pedagógicos dos cursos de graduação?

Nesse sentido, este trabalho faz parte de uma pesquisa que objetiva estudar o ensino das disciplinas da área de Ciências Sociais em cursos de graduação, principalmente nas modalidades licenciatura e bacharelado. Em um primeiro momento, realizou-se o levantamento das características da oferta da disciplina de Sociologia em 43 cursos de licenciatura presenciais de uma universidade pública situada no estado de Minas Gerais e constatou-se que $76,7 \%$ desses cursos ofertavam disciplinas com conteúdo sociológico, sendo $97,9 \%$ obrigatórias. Entre essas disciplinas, 87,5\% estavam situadas nas matrizes curriculares entre o primeiro e o terceiro períodos dos cursos analisados (PEREIRA, 2019).

Assim, dando continuidade ao estudo, este artigo verifica como as disciplinas da área de Ciências Sociais - Antropologia, Ciência Política e Sociologia - estão sendo ofertadas em cursos de bacharelado presenciais na mesma universidade pública situada no estado de Minas Gerais, bem como estão organizadas nos projetos pedagógicos desses cursos.

A relevância deste artigo reside no fato de apresentar as características da oferta das disciplinas das principais áreas das Ciências Sociais em cursos de formação de profissionais em nível superior, além de contribuir para o debate sobre seus ensinos na graduação e mostrar a importância desses conteúdos. Salienta-se que este relato não tem a pretensão de esgotar a revisão sobre a institucionalização das Ciências Sociais no país, tampouco apresentar todas as informações a respeito das reformas e políticas curriculares do ensino superior, respeitados os limites e o objetivo da pesquisa.

Dessa forma, este artigo se divide em quatro seções, além desta introdução. A primeira traz algumas informações sobre o ensino de Ciências Sociais no país, a segunda descreve os procedimentos metodológicos utilizados para o desenvolvimento deste estudo e a terceira seção apresenta os resultados obtidos a partir do levantamento dos dados da instituição de ensino superior selecionada e a discussão. Por fim, as considerações finais assinalam algumas reflexões e apontam possibilidades de continuidade da pesquisa.

\section{APONTAMENTOS SOBRE O ENSINO DE CIÊNCIAS SOCIAIS EM CURSOS DE GRADUAÇÃO}

Como foi salientado anteriormente, ainda não há uma literatura nacional robusta que evidencie a reflexão sobre o ensino das disciplinas Antropologia, Ciência Política e/ou Sociologia, que integram as principais áreas das Ciências Sociais no nível superior.

Dentro do subcampo de pesquisa ensino de Sociologia, as características da oferta desta disciplina têm sido mais estudadas na Educação Básica. Bodart e Pereira (2017) afirmaram que esse subcampo foi formado tardiamente devido à descontinuidade da obrigatoriedade da Sociologia como disciplina escolar e, na atualidade, as pesquisas sobre o ensino de Sociologia versam mais sobre sua presença 
PEREIRA, O. A. V

no Ensino Médio, o crescente número de cursos de Ciências Sociais na modalidade licenciatura e a produção de materiais didáticos na área.

Furlin (2020, p. 3) aponta que a introdução da Sociologia no país teve o objetivo de, "[...] sobretudo no ensino superior, [...] de reproduzir a nova visão de mundo no país que se havia constituído em um república, e questionar as ideias que davam sustentação à antiga ordem social". Lima e Cortes (2013, p. 417) afirmam que no país "[...] a Sociologia surge como sinônimo de Ciências Sociais. Antropologia, Ciência Política e Sociologia conviveram em um mesmo campo construindo espaços comuns de discussão [...]" e, ao mesmo tempo, se fortaleciam enquanto disciplinas.

Meucci (2007) apontou que a Sociologia surgiu no ano de 1891 na Educação Básica, permanecendo pouco tempo e reaparecendo novamente no início do século XX, em duas situações, na década de 1920. A primeira em 1925, quando o seu conteúdo foi cobrado nos exames de vestibular, passando a fazer parte do rol dos cursos complementares de preparação para os alunos ingressarem nos cursos de graduação a partir de 1931, e quando passou a compor o currículo de formação dos professores que estudavam nas Escolas Normais a partir da segunda metade dos anos 1920, constituindo a segunda situação de inserção dessa disciplina.

Simultaneamente ao processo histórico de inserção da disciplina de Sociologia na Educação Básica e Superior brasileiras, cabe apresentar algumas informações sobre o processo de institucionalização das Ciências Sociais no país. Silva e Silva (2012, p. 100) apontam que a institucionalização aconteceu em momentos diferentes, sendo que o primeiro compreendeu o período de 1870 a 1930, em que intelectuais não especializados procuravam interpretar o Brasil. Esses autores geralmente utilizavam referenciais evolucionistas e se pautavam por fatores biológicos, porém no final deste período surgiram trabalhos com "forte preocupação em elaborar uma 'Teoria geral do Brasil', com destaque para os aspectos políticos [...]".

Após esse primeiro período, entre 1930 e 1940, houve uma época transitória. O país passava por um processo inicial de modernização e dois acontecimentos contribuíram para a institucionalização das Ciências Sociais. O primeiro foi a obrigatoriedade da disciplina de Sociologia no ensino secundário e superior; o segundo, a criação dos cursos superiores em Ciências Sociais nas universidades brasileiras, sendo os primeiros na Escola Livre de Sociologia e Política, em 1933, e a Seção de Sociologia e Ciência Política da Faculdade de Filosofia da Universidade de São Paulo, em 1934, ambos na cidade de São Paulo (CANDIDO, 2006; SEGATTO; BARIANI, 2010; SILVA; SILVA, 2012).

Após a década de 1940, houve o segundo momento de institucionalização das Ciências Sociais no país. A partir dessa época, a análise científica da sociedade no Brasil começou com a chegada de pesquisadores estrangeiros que, liderados por Florestan Fernandes, constituíram uma nova forma de produzir ciência na área (SILVA; SILVA, 2012). Assim, os estudos passaram a ser realizados embasados em teorias e metodologias inovadoras, o que contribuiu para que nos anos 1950 e 1960 a investigação social adquirisse um contorno próprio, se consolidasse e, consequentemente, institucionalizasse as Ciências Sociais no país. Essa institucionalização também ocorreu por causa do progresso da organização universitária e da criação de centros de investigação governamentais.

Liedke Filho (2005), ao analisar a história da Sociologia e a evolução de sua institucionalização enquanto disciplina acadêmica no país, aponta que no ano de 1936 o 
país tinha dois cursos de graduação em Ciências Sociais e, em 1976, 83 cursos. Este fato explica-se pela reforma universitária de 1968 e a expansão do ensino superior também na rede privada.

A partir da década de 1980, a Sociologia, a Antropologia e a Ciência Política se fortaleceram enquanto disciplinas por causa do aumento do número de cursos de graduação e pós-graduação em Ciências Sociais e, também, devido à atuação de suas organizações associativas acadêmicas, tais como a Sociedade Brasileira de Sociologia (SBS) criada em 1950, a Associação Brasileira de Antropologia (ABA) em 1953 e a Associação Brasileira de Ciência Política (ABCP) em 1986 (LIMA; CORTES, 2013).

Assim, a disciplina de Sociologia no país foi ofertada inicialmente na Educação Básica e depois na Educação Superior, a partir da criação dos cursos de graduação em Ciências Sociais na década de 1930, passando também a ter reconhecimento e garantia do seu lugar no meio intelectual (MEUCCl, 2007).

$\mathrm{Na}$ atualidade, a Sociologia e as outras disciplinas das Ciências Sociais tornam-se cada vez mais imprescindíveis para uma "construção intelectual" que ultrapassa a "produção universitária", orientadas para a compreensão mais plural da vida social e dos "dilemas e desafios colocados no mundo contemporâneo" (PERLATTO, 2017, p. 146), pois as Ciências Sociais contêm áreas de conhecimento que auxiliam os estudantes a descontruírem e refletirem sobre os aspectos que constituem o tecido social.

Santos $(2018$, p. 636) realizou um levantamento sobre a produção de estudos na área de ensino de Sociologia na Educação Superior, com ênfase em sua ocorrência em cursos de graduação em Enfermagem, e constatou que havia poucos trabalhos realizados nessa área. A explicação apresentada pela autora para tal fato foi que a área de ensino da Sociologia, assim como das outras disciplinas das Ciências Sociais, configura uma posição de menor prestígio diante das outras áreas de pesquisa desse campo do saber. "[...] Essa situação culmina em uma espécie de hierarquização das atividades universitárias, já que há uma sobrevalorização da pesquisa em detrimento do ensino, uma sobrevalorização da pós-graduação em detrimento da graduação", acarretando uma descontinuidade da produção pedagógica e científica em torno dos fenômenos do ensino das disciplinas da área.

Ao relatar a experiência de ministrar a disciplina de Sociologia para alunos de cursos de graduação em uma instituição privada, Andrade (2018) apontou a contradição existente na atualidade sobre a perspectiva de a disciplina proporcionar uma visão crítica diante das crises sociais, ao mesmo tempo que há interesses de setores da sociedade em naturalizá-las por meio do sentido de normalidade atribuído em seus discursos. Assim, é necessário repensar o ensino de Sociologia, bem como o de outras disciplinas de Ciências Sociais e Humanas diante da precarização das condições e dos direitos sociais em relação aos interesses do capital. Continuando dessa forma, a educação passaria a ter apenas um objetivo: formar trabalhadores e não cidadãos críticos capazes de reconhecer como ocorre o processo de naturalização do ódio por trás de uma pretensa moralidade imposta por grupos conservadores no cenário social, por exemplo.

Sartori (2012) pesquisou as características do ensino de Antropologia nos cursos de Pedagogia em instituições de ensino superior da Região Sul do Brasil e afirmou que a 
PEREIRA, O. A. V

inclusão dessa disciplina nos currículos dos referidos cursos de licenciatura colaborou para que houvesse o reconhecimento, a compreensão e o respeito às diferenças na formação dos futuros professores, profissionais que atuarão na formação de outros profissionais.

A partir da década de 1990 ocorreram modificações no país no âmbito da Educação Superior, sobretudo para atender às políticas neoliberais e ao processo de adequação do Estado à globalização. Rosa (2014) assinala que as premissas de documentos de organismos internacionais, tais como o Banco Mundial, a Organização das Nações Unidas (ONU), a Organização das Nações Unidas para a Educação, a Ciências e a Cultura (Unesco) entre outros, influenciaram a elaboração das políticas educacionais nacionais.

Entre as alterações pautadas pela Lei de Diretrizes e Bases de 1996 (BRASIL, 1996) para o ensino de graduação, destacam-se: a "criação de diretrizes curriculares nacionais para os cursos de graduação por meio de comissões" especializadas de cada área do saber; a elaboração dos projetos pedagógicos dos cursos que deveriam atender às premissas dessas diretrizes e flexibilizar os currículos; a "[...] intensificação das discussões internacionais e nacionais sobre diplomas e perfis profissionais" para contemplar as especificidades da sociedade contemporânea; a definição de padrões de qualidade para os cursos de graduação entre outras (AMARAL, 2014, p. 35). Essas orientações foram corroboradas pelo Parecer n. 776, de 3 de dezembro de 1997, aprovado pela Câmara de Educação Superior do Conselho Nacional de Educação, e passaram a ser utilizadas para elaborar essas diretrizes (BRASIL, 1997).

As reformas na Educação Superior começaram na década de 1990 e especificamente nos anos 2000, na graduação, elas "[...] foram apresentadas como ferramenta para o desenvolvimento econômico do país, e esse nível de ensino passou a se submeter cada vez mais ao direcionamento do mercado" (ROSA, 2014, p. 238).

De uma forma geral, observa-se a tendência de redução do tempo previsto para a conclusão dos cursos de graduação sob a ótica de que esta etapa é a inicial da formação continuada e, consequentemente, para diminuir os índices de evasão e diversificar as possibilidades de formação. As diretrizes curriculares nacionais para os cursos de graduação geralmente recomendam uma formação orientada para a cidadania, com a inclusão de objetivos referentes aos preceitos éticos e reflexivos por meio da inserção nos currículos de disciplinas da área de Ciências Humanas e Sociais, tais como Antropologia, Sociologia, História, Ciência Política, Psicologia, Filosofia, entre outras (AMARAL, 2014). Inserção esta que também deveria ser mais pesquisada por cientistas sociais, por exemplo, com a finalidade de verificar de quais formas essas disciplinas, quando presentes nos currículos dos cursos de graduação, contribuem para a formação de profissionais em diversas áreas do saber.

A presença da disciplina de Sociologia nas matrizes curriculares dos cursos de graduação, fora dos cursos de Ciências Sociais, foi legitimada por possibilitar o desenvolvimento do pensamento crítico, da emancipação, da autonomia e do reconhecimento do estudante como cidadão (AMARAL, 2014). Brunetta e Amaral (2017) salientam, porém, que o significado de cidadania não é efetivamente definido nos documentos que orientam a elaboração dos currículos.

Oliveira (2013) ressalta que a Sociologia foi introduzida nos currículos dos cursos de graduação como uma disciplina científica e que, dessa forma, possibilita a 
conscientização sobre as diferenças sociais, políticas e culturais e suas perspectivas. Possibilidades estas que podem ser estendidas também à Antropologia e à Ciência Política. Santos (2018) ressalta a necessidade de uma análise sociológica dos currículos, a qual permitiria o debate sobre a finalidade e a identidade dessas disciplinas dentro dos contextos históricos e institucionais das universidades e faculdades.

A próxima seção apresenta os procedimentos metodológicos adotados para examinar algumas características da oferta de disciplinas da área de Ciências Sociais, em cursos de bacharelado presenciais de uma universidade pública, no sentido de ilustrar alguns desses apontamentos.

\section{Metodologia}

Tratou-se de uma pesquisa descritiva documental. Em um primeiro momento, averiguou-se que a universidade pública do estado de Minas Gerais, selecionada para a realização deste estudo, ofertava 115 cursos de graduação presenciais no segundo semestre do ano de 2019, sendo 44 cursos de licenciatura, 61 cursos de bacharelado e 10 tecnólogos.

Em seguida, foram analisadas as características da oferta das disciplinas da área de Ciências Sociais nos 61 cursos de bacharelados presenciais dessa instituição de ensino entre os meses de janeiro a abril do corrente ano. Os cursos de bacharelado foram categorizados de acordo com as áreas do conhecimento do Conselho Nacional de Desenvolvimento Científico e Tecnológico (CNPq) que são: 1) Ciências Exatas e da Terra; 2) Ciências Biológicas; 3) Engenharias; 4) Ciências da Saúde; 5) Ciências Agrárias; 6) Ciências Sociais Aplicadas; 7) Ciências Humanas e 8) Linguística, Letras e Artes (CNPq, 2020).

Após a organização dos cursos por áreas do conhecimento, mensurou-se em quais cursos eram ofertadas as disciplinas da área de Ciências Sociais. Depois, as disciplinas foram distribuídas entre Antropologia, Ciência Política, Sociologia e Tópicos em Ciências Sociais de acordo com os seus títulos e a leitura de suas ementas disponibilizadas nos Projetos Pedagógicos dos cursos e, também, classificadas como obrigatórias ou optativas. Em relação às disciplinas obrigatórias, verificou-se em quais períodos elas eram ofertadas.

Não foram analisadas as disciplinas da área de metodologia científica em suas várias nomenclaturas por compreender que tais disciplinas poderiam conter conteúdos que abarcam outras áreas do conhecimento, além das Ciências Sociais.

Após a organização das informações, os resultados foram dispostos em tabelas e serão apresentados e discutidos na próxima seção.

\section{RESULTADOS E DISCUSSÃO}

Foram identificados e pesquisados os sites institucionais de 61 cursos de bacharelado presenciais de uma universidade pública. Entre estes, 41 cursos tinham os seus projetos pedagógicos publicados em seus sites e ofertavam disciplinas da área de Ciências Sociais e 20 não tinham esses projetos disponibilizados. O Projeto Pedagógico 
PEREIRA, O. A. V

de Curso (PPC) de um curso de graduação detalha os princípios norteadores, o perfil do egresso, a organização e estrutura curricular do curso e outras informações pertinentes ao desenvolvimento do seu processo de ensino e aprendizagem.

A Tabela 1 apresenta a distribuição dos cursos por área de conhecimento e o número das disciplinas ofertadas da área de Ciências Sociais.

Tabela 1 - Distribuição de cursos de bacharelado presenciais por área do conhecimento e de disciplinas da área de Ciências Sociais nesses cursos, 2020

\begin{tabular}{ccc}
\hline Área do Conhecimento & Número de cursos & Número de disciplinas \\
\hline Ciências Exatas e da Terra & 4 & 8 \\
Ciências Biológicas & 1 & 1 \\
Engenharias & 6 & 7 \\
Ciências da Saúde & 6 & 7 \\
Ciências Sociais Aplicadas & 20 & 129 \\
Ciências Humanas & 1 & 3 \\
Linguística, Letras e Artes & 3 & 6 \\
Total & 41 & 161 \\
\hline
\end{tabular}

Fonte: Projetos pedagógicos dos cursos de bacharelado presenciais de uma universidade pública. Elaborada pela autora.

A ordem de apresentação das áreas do conhecimento segue a ordem apresentada pela Tabela das Áreas do Conhecimento do CNPq (CNPq, 2020). Há maior concentração de disciplinas da área de Ciências Sociais ofertadas em cursos da área de Ciências Sociais Aplicadas, em que destacam-se os cursos de Direito, Serviço Social, Administração, Jornalismo, Comunicação Social e Turismo. Também é importante ressaltar que a instituição de ensino superior selecionada para esta pesquisa é multicampi e, dessa forma, ela oferece esses cursos em mais de uma unidade.

Não foi encontrada nenhuma disciplina da área de Ciências Sociais ofertada pelos cursos da área do conhecimento em Ciências Agrárias. Esse fato pode ser explicado porque os cursos ofertados dessa área não tinham os projetos pedagógicos divulgados em seus sites institucionais.

Todos os cursos de bacharelado presenciais estudados e que tinham seus projetos pedagógicos publicados $(n=41)$ ofertavam pelo menos uma disciplina da área de Ciências Sociais, o que demonstra a inserção dessa área do saber nos diferentes cursos de graduação de outras áreas do conhecimento e a possibilidade de contribuição de sua diversidade teórica e metodológica para o desenvolvimento do conhecimento e das habilidades dos graduandos.

Entre as finalidades da Educação Superior estabelecidas pela Lei de Diretrizes e Bases da Educação Nacional (BRASIL, 1996), em seu Art. 43, destacam-se:

I - estimular a criação cultural e o desenvolvimento do espírito
científico e do pensamento reflexivo;
II - formar diplomados nas diferentes áreas de conhecimento, aptos
para a inserção em setores profissionais e para a participação no
desenvolvimento da sociedade brasileira, e colaborar na sua
formação contínua;
III- incentivar o trabalho de pesquisa e investigação científica,
visando o desenvolvimento da ciência e da tecnologia e da criação

Inter-Ação, Goiânia, v.46, n.1, p. 309-322, jan./mar. 2021. Disponível em: <http://dx.doi.org/10.5216/ia.v45i3.65076>. 


\begin{abstract}
e difusão da cultura, e, desse modo, desenvolver o entendimento do homem e do meio em que vive;

[...]

$\mathrm{VI}$ - estimular o conhecimento dos problemas do mundo presente, em particular os nacionais e regionais, prestar serviços especializados à comunidade e estabelecer com esta uma relação de reciprocidade.
\end{abstract}

As disciplinas da área de Ciências Sociais são imprescindíveis para que essas finalidades sejam contempladas durante a formação dos estudantes de cursos de graduação por meio de seus diferentes autores, teorias e métodos próprios para investigar a realidade social, conhecer as particularidades e a riqueza cultural dos diferentes grupos sociais e étnicos, compreender as organizações, as instituições e os aspectos políticos que constituem uma dada sociedade, e identificar os comportamentos, os problemas e as características dos atores sociais e da coletividade.

A Tabela 2 expõe a distribuição das disciplinas ofertadas pelos cursos de bacharelado presenciais de acordo com as áreas das Ciências Sociais. Verificou-se que, pela heterogeneidade das áreas de conhecimento dos cursos de bacharelado, as disciplinas ofertadas abarcavam todas as áreas das Ciências Sociais, ou seja, Antropologia, Ciência Política, Sociologia e algumas apresentavam temas/tópicos das três áreas das Ciências Sociais, além de tópicos de outras Ciências Humanas. Geralmente, estas últimas eram intituladas "Tópicos em Ciências Sociais", "Tópicos em Ciências Humanas e Sociais" e/ou "Humanidades e Ciências Sociais".

Tabela 2 - Distribuição das disciplinas da área de Ciências Sociais ofertadas pelos cursos de bacharelado presenciais, 2020

\begin{tabular}{ccc}
\hline Área das Ciências Sociais & N & $\%$ \\
\hline Antropologia & 34 & 21,1 \\
Ciência Política & 39 & 24,2 \\
Sociologia & 71 & 44,1 \\
Tópicos em Ciências Sociais e outras & 17 & 10,6 \\
Total & 161 & 100 \\
\hline
\end{tabular}

Fonte: Projetos pedagógicos dos cursos de bacharelado presenciais de uma universidade pública. Elaborada pela autora.

A disciplina de Sociologia foi a mais ofertada nos cursos analisados $(44,1 \%)$ (Tabela 2). Brunetta e Amaral (2017) e Furlin (2020, p. 4) concordam que ao mesmo tempo que houve o aumento do número de cursos de graduação ofertados a partir da década de 1990, tanto na rede pública quanto na privada, ocorreu também o aumento da oferta da disciplina de Sociologia. Entretanto, essa disciplina geralmente tem uma carga horária reduzida e um caráter introdutório - "Introdução à Sociologia" -, além de sofrer "[...] muitas vezes, processos de instrumentalização e de disputas departamentais."

Ocorre que a ciência sociológica surgiu, com o objetivo de estudar a dinâmica dessa nova mentalidade social, no momento em que houve a dissolução da mentalidade feudal, com a desagregação da comunidade, a emergência de um novo modo de 
PEREIRA, O. A. V

produção - o capitalista -, que inaugurou uma nova sociedade com a mentalidade de uma nova classe - a burguesia -, instituída com base principalmente nas desigualdades.

Carniel e Bueno (2018), ao estudarem o ensino de Sociologia e seus públicos, afirmam que a Sociologia também contribui para uma formação científica dos estudantes sobre a realidade social. Santos (2018, p. 642) assegura que ao apresentar as questões sociais presentes na atualidade aos alunos dos cursos de graduação em Enfermagem "[...] com base na sociologia clássica, [possibilita] o acesso deles ao conhecimento especializado [...]", o que também oportuniza que eles posteriormente estudem outros autores contemporâneos da área de Sociologia e incorporem mais elementos para conhecer, analisar situações e apontar possíveis soluções aos problemas identificados em um dado contexto social.

Uma vez que a realidade social possui múltiplas dimensões e aspectos que podem ser analisados com base em teorias e métodos diferentes e, às vezes, divergentes, a "pluralidade teórico-epistemológica" das Ciências Sociais colabora para que o estudante escolha posicionamentos que apontam para teorias e métodos que sejam mais adequados para analisar e compreender os fenômenos sociais de uma sociedade (AMARAL, 2014). Salienta-se que as outras disciplinas da área de Ciências Sociais também foram ofertadas de forma significativa entre os cursos presenciais de bacharelado estudados, uma vez que eles eram de diferentes áreas de conhecimento, como já mencionado.

A Tabela 3 apresenta a distribuição das disciplinas obrigatórias e optativas ofertadas pelos cursos estudados. Entre as disciplinas optativas, $44,4 \% \quad(n=20)$ compreendiam conteúdos da Sociologia.

Tabela 3 - Distribuição das disciplinas da área de Ciências Sociais por natureza nos cursos de bacharelado presenciais, 2020

\begin{tabular}{ccc}
\hline Natureza das disciplinas & $\mathbf{N}$ & $\%$ \\
\hline Obrigatórias & 116 & 72,0 \\
Optativas & 45 & 28,0 \\
Total & 161 & 100 \\
\hline
\end{tabular}

Fonte: Projetos pedagógicos dos cursos de bacharelado presenciais de uma universidade pública. Elaborada pela autora.

A Tabela 4 mostra a distribuição das disciplinas obrigatórias da área de Ciências Sociais ofertadas pelos cursos de bacharelado por períodos.

Tabela 4 - Distribuição das disciplinas obrigatórias da área de Ciências Sociais por períodos nos cursos de bacharelado presenciais, 2020

\begin{tabular}{ccc}
\hline Disciplinas obrigatórias por períodos & $\mathrm{N}$ & $\%$ \\
\hline $1^{\circ}$ ao $3^{\circ}$ período & 91 & 78,4 \\
$4^{\circ}$ ao $6^{\circ}$ período & 14 & 12,1 \\
$7^{\circ}$ ao $9^{\circ}$ período & 9 & 7,8 \\
$10^{\circ}$ período & 2 & 1,7 \\
Total & 116 & 100 \\
\hline
\end{tabular}

Fonte: Projetos pedagógicos dos cursos de bacharelado presenciais de uma universidade pública. Elaborada pela autora. 
A maioria, ou seja, $78,4 \%$ das disciplinas obrigatórias da área de Ciências Sociais eram ofertadas nos períodos iniciais dos cursos de bacharelado presenciais que tiveram seus projetos pedagógicos de cursos analisados e, entre estas, $41,7 \%(n=38)$ no primeiro período. Nenhuma disciplina dessa natureza foi ofertada depois do décimo período desses cursos.

Outra característica observada foi a oferta de disciplinas que apresentavam tópicos das três áreas das Ciências Sociais que, quando obrigatórias, $64,7 \%$ eram ofertadas nos períodos finais dos cursos analisados, ou seja, a partir do $7^{\circ}$ período (Tabela 4).

Uma possível explicação para que essas disciplinas sejam mais ofertadas nos períodos iniciais é que as disciplinas da área de Ciências Sociais são geralmente consideradas propedêuticas, ou seja, elas proporcionam uma formação introdutória aos estudantes, os quais são preparados com conhecimentos mais abrangentes para contextualizarem as questões sociais, humanas e éticas, no sentido de prepará-los para uma formação mais voltada para a área do próprio curso, ou seja, é oportunizada uma formação inicial para proporcionar depois uma formação mais específica aos graduandos das diferentes áreas do conhecimento.

\section{CONSIDERAÇÕES FINAIS}

O levantamento realizado nos projetos pedagógicos dos cursos de bacharelado presenciais de uma universidade pública mostrou que $67,2 \%$ dos cursos ofertavam pelo menos uma disciplina da área de Ciências Sociais e, entre essas disciplinas, constatou-se que $72,0 \%$ eram obrigatórias, $78,4 \%$ ofertadas nos períodos iniciais dos cursos e $44,1 \%$ eram de Sociologia ou compreendiam conteúdos desta disciplina. É claro que esses resultados revelam as características da oferta dessas disciplinas em um único universo e, a partir de então, sugere-se que este levantamento seja realizado em outras instituições de ensino superior para ampliar o conhecimento sobre essas características.

Infelizmente, nem todos os cursos tinham seus projetos pedagógicos publicados em seus sites oficiais, o que dificultou a identificação de, talvez, um número maior de disciplinas ofertadas e a ampliação da compreensão das características dessa oferta. A falta de uma agenda de pesquisa e pouca literatura nacional que aborde as características do ensino das disciplinas da área de Ciências Sociais na formação de estudantes de graduação também foi um outro percalço encontrado quando se delineou a proposta desta pesquisa.

Portanto, os desafios em um futuro próximo serão mostrar como as Ciências Sociais são relevantes para a compreensão das transformações que estão acontecendo na atualidade e promover o diálogo com outras áreas do conhecimento a partir da presença das disciplinas de Antropologia, Ciência Política e Sociologia nos currículos dos diversos cursos de graduação. Currículos estes que também deverão levar em consideração os aspectos históricos, culturais e políticos do contexto social no qual estão inseridas as instituições de ensino superior, os cursos e os estudantes.

Nesse intuito, sugere-se que os currículos dos cursos de graduação que contenham disciplinas da área de Ciências Sociais se tornem objetos de estudo dentro 
PEREIRA, O. A. V

de uma abordagem sociológica que congregue as especificidades das áreas de ensino de suas disciplinas - Antropologia, Ciência Política e Sociologia - com outras áreas de conhecimento e formação.

E como possibilidades de continuação em outras pesquisas dentro da temática aqui retratada pretende-se traçar o perfil dos docentes que ministram as disciplinas desta área do saber nos cursos de graduação presenciais, na mesma universidade deste estudo, e averiguar quais estratégias e práticas de ensino e aprendizagem estão sendo mais utilizadas por eles no cotidiano das salas de aula, uma vez que esses são os espaços pelos quais as teorias e os métodos dessas ciências são apresentados aos estudantes.

Artigo recebido em: $18 / 08 / 2020$

Aprovado para publicação em: 18/11/2020

\section{OFFERING SOCIAL SCIENCES SUBJECTS IN BACHELOR'S DEGREES OF A PUBLIC UNIVERSITY}

ABSTRACT: This descriptive documentary research assesses how the chief subjects of Social Sciences, i.e. Anthropology, Political Science and Sociology, are being offered in bachelor's degrees. Sixty-one in-person bachelor's degrees were identified in a public university of Minas Gerais State, Brazil. Among them, forty-one offered 161 subjects in the Social Sciences field in which $72 \%$ were compulsory and $78.4 \%$ were taught during the initial periods. It was also observed that different bachelor degrees from several areas were offering at least one subject from the area of Applied Social Sciences. This highlights the inclusion of these subjects into different curriculum frameworks as well as the contribution of different theories and methodologies from those courses for the training of undergraduate students.

KEYWORDS: Social Science Teaching. Undergraduate Degree. Curriculum Degree's Educational Projects.

LA OFERTA DE DISCIPLINAS EN EL ÁREA DE CIENCIAS SOCIALES EN CURSOS DE BACHILLERATO DE UNA UNIVERSIDAD PÚBLICA

RESUMEN: En este artículo se evalúa como las principales áreas en Ciencias Sociales, es decir Antropología, Ciencia Política y Sociología, están siendo ofrecidas en cursos de pre-grado de bachiller. Esta es una investigación documental descriptiva. Se identificaron 61 cursos de bachillerato presencial ofrecidos en una universidad pública en el estado de Minas Gerais, Brasil. De estos, 41 cursos ofrecieron 161 asignaturas en el área de Ciencias Sociales y, entre estas asignaturas, $72 \%$ fueron obligatorias y $78.4 \%$ impartidas en los periodos iniciales. Se encontró que los cursos de bachiller de distintas áreas del conocimiento ofrecían al menos una disciplina en el área de Ciencias Sociales Aplicadas, destacando la inserción de estas disciplinas y la posibilidad de aportar sus diferentes teorías y metodologías a la formación de estudiantes de pregrado.

PALABRAS CLAVE: Docencia de Ciencias Sociales. Graduado Universitario. Currículo. Proyectos de Cursos Pedagógicos.

Inter-Ação, Goiânia, v.46, n.1, p. 309-322, jan./mar. 2021. Disponível em: <http://dx.doi.org/10.5216/ia.v45i3.65076>. 


\section{REFERÊNCIAS}

AMARAL, L. H. O ensino de sociologia nos cursos de graduação da UFSC: uma contribuição ao debate sociológico e pedagógico, 2014. Trabalho de Conclusão de Curso (Licenciatura em Ciências Sociais) - Universidade Federal de Santa Catarina, Florianópolis, 2014. Disponível em:

https://repositorio.ufsc.br/xmlui/bitstream/handle/123456789/123797/TCL\%20LETICIA \%20HUMMEL\%20DO\%20AMARAL.pdf?sequence=1\&isAllowed=y. Acesso em: 20 fev. 2020.

ANDRADE, R. A. O. Apresentando sociologia para não sociólogos: perspectivas de ensino da disciplina em graduações no ensino superior. Cadernos da Associação Brasileira de Ensino de Ciências Sociais, Rio de Janeiro, v. 2, n. 1, p. 115-123, jan./jun. 2018. Disponível em: https://abecs.com.br/revista/index.php/cabecs/article/view/87/81.

Acesso em: 13 fev. 2020.

BODART, C. N.; PEREIRA, T. I. Breve balanço do subcampo "ensino de Ciências Sociais" no Brasil e o papel da Associação Brasileira de Ensino de Ciências Sociais - ABECS. Cadernos da Associação Brasileira de Ensino de Ciências Sociais, Rio de Janeiro, v. 1, n. 1, p. 110, jan./jun. 2017. Disponível em: https://abecs.com.br/revista/index.php/cabecs/article/view/40. Acesso em: 13 fev. 2020.

BRASIL. Lei de Diretrizes e Bases da Educação Nacional. Brasília: Ministério da Educação, 1996. Disponível em: http://www.planalto.gov.br/ccivil_03/leis//9394.htm. Acesso em: 10 maio 2020.

BRASIL. Parecer n. 776, de 3 de dezembro de 1997. Brasília: Ministério da Educação, 1997. Disponível em:

http://portal.mec.gov.br/index.php?option=com_docman\&view=download\&alias=1541 21-pces776-97\&category_slug=agosto-2020-pdf\&ltemid=30192. Acesso em: 23 nov. 2020.

BRUNETTA, A. A.; AMARAL, L. H. Potencialidades do Ensino de Sociologia para o desenvolvimento da formação profissional em Cursos de Graduação da Universidade Federal de Santa Catarina. Revista Desenvolvimento, Fronteiras e Cidadania, Ponta Porã, v. 1, n. 1, p. 56-79, jul. 2017. Disponível em: https://periodicosonline.uems.br/index.php/fronteiracidadania/article/view/2171/1706. Acesso em: 23 nov. 2020.

CANDIDO, A. A sociologia no Brasil.Tempo Social, São Paulo, v. 18, n. 1, p. 271-301, junho de 2006. Disponível em: http://www.revistas.usp.br/ts/article/view/12503. Acesso em: 29 jun. 2020. 
PEREIRA, O. A. V

CARNIEL, F.; BUENO, Z. P. O ensino de sociologia e os seus públicos. Educação \& Sociedade, Campinas, v. 39, n. 144, p. 671-685, jul./set. 2018. Disponível em: https://www.scielo.br/scielo.php?script=sci_arttext\&pid=S0101-73302018000300671. Acesso em: 03 fev. 2020.

CONSELHO NACIONAL DE DESENVOLVIMENTO CIENTÍFICO E TECNOLÓGICO (CNPq). Tabela de Áreas do conhecimento. Disponível em: http://www.cnpq.br/documents/10157/186158/TabeladeAreasdoConhecimento.pdf. Acesso em: 20 fev. 2020.

FURLIN, N. A Sociologia na Educação Superior: sentidos produzidos nas narrativas de estudantes de Odontologia da Universidade Estadual de Maringá. Educação em Revista, Belo Horizonte, v. 36, e219614, 2020. Disponível em: http://www.scielo.br/scielo.php?script=sci_arttext\&pid=S010246982020000100227\&lng=en\&nrm=iso. Acesso em: 20 nov. 2020.

INSTITUTO NACIONAL DE ESTUDOS E PESQUISAS EDUCACIONAIS ANÍSIO TEIXEIRA (INEP). Sinopse Estatística da Educação Superior 2018. Brasília: Inep, 2019. Disponível em: http://portal.inep.gov.br/basica-censo-escolar-sinopse-sinopse. Acesso em: 05 fev. 2020.

LIEDKE FILHO, E. D. A Sociologia no Brasil: história, teorias e desafios. Sociologias, Porto Alegre, n. 14, p. 376-437, dez. 2005. Disponível em: http://www.scielo.br/scielo.php?script=sci_arttext\&pid=S151745222005000200014\&lng=pt\&nrm=iso. Acesso em: 21 nov. 2020.

LIMA, J. C.; CORTES, S. M. V. A sociologia no Brasil e a interdisciplinaridade nas ciências sociais. Civitas, Porto Alegre, v. 13, n. 3, p. 416-435, set./dez. 2013. Disponível em: https://revistaseletronicas.pucrs.br/ojs/index.php/civitas/article/view/16522. Acesso em: 21 nov. 2020.

MEUCCl, S. Sobre a rotinização da sociologia no Brasil: os primeiros manuais didáticos, seus autores, suas expectativas. Mediações, Londrina, v. 12, n. 1, p. 31-66, jan./jun. 2007. Disponível em: http://www.uel.br/revistas/uel/index.php/mediacoes/article/view/3386. Acesso em: 03 fev. 2020.

OLIVEIRA, A. Ensino de sociologia, Estado Nacional e reflexividade: dilemas da Modernidade. In: OLIVEIRA, L. F. (org.). Ensino de Sociologia: desafios teóricos e pedagógicos para as Ciências Sociais. Seropédica: Editora da UFRRJ, 2013.

PEREIRA, O. A. V. Características da oferta da disciplina Sociologia em cursos de licenciatura de uma universidade pública In: CONGRESSO BRASILEIRO DE SOCIOLOGIA, 19., 2019, Florianópolis, SC. Anais [...]. São Paulo: Sociedade Brasileira de Sociologia, 2019. Tema: em que sociedade vivemos? Disponível em: file:///D:/PASTAS\%20DE\%20USU\%C3\%81RIO/downloads/Trabalho_Completo_SBS_201 9_Orcione_Pereira.pdf. Acesso em: 10 fev. 2020. 
PERLATTO, F. Sociologia e Ciências Sociais na graduação: especialização \& imaginação interdisciplinar. In: BOMENY, H. (Org.). O ensino de sociologia na graduação. São Paulo: Annablume, 2017.

ROSA, C. M. Marcos legais e a Educação Superior no século XXI. Revista Eletrônica de Educação, São Carlos, v. 8, n. 3, p. 236-250, 2014. Disponível em: http://www.reveduc.ufscar.br/index.php/reveduc/article/view/1029/369. Acesso em: 23 nov. 2020.

SANTOS, E. S. O ensino de sociologia nos cursos de enfermagem: discutindo possibilidades curriculares. Revista Brasileira de Estudos Pedagógicos, Brasília, v. 99, n. 263, p. 633-648, set./dez. 2018. Disponível em:

https://www.scielo.br/scielo.php?script=sci_arttext\&pid=S2176-

66812018000300633\&lng=en\&nrm=iso\&tlng=pt. Acesso em: 15 fev. 2020.

SARMENTO, R.; REZENDE, D. L.; SANTOS JÚNIOR, H. F. Para além do horizonte: ensino em Ciência Política no interior de Minas Gerais. Civitas, Porto Alegre, v. 19, n. 3, p. 605-624, set./dez. 2019. Disponível em:

https://revistaseletronicas.pucrs.br/ojs/index.php/civitas/article/view/33462/19224. Acesso em: 20 nov. 2020.

SARTORI, A. J. O ensino da Antropologia para quem não vai ser antropólogo. Percursos, Florianópolis, v. 13, n. 1, p. 99-119, jan./jun. 2012. Disponível em: http://www.revistas.udesc.br/index.php/percursos/article/view/2522. Acesso em: 12 fev. 2020.

SEGATTO, J.; BARIANI, E. As Ciências Sociais no Brasil: trajetória, história e institucionalização. Em pauta, Rio de Janeiro, v. 7, n. 25, p. 201-213, jul. 2010. Disponível em: https://www.epublicacoes.uerj.br/index.php/revistaempauta/article/view/2922/2086. Acesso em: 10 jul. 2020.

SILVA, C. L.; SILVA, R. S. A institucionalização das Ciências Sociais no Brasil: percalços e conquistas. Impulso, Piracicaba, v. 22, n. 54, p. 97-106, maio/ago. 2012. Disponível em: https://www.metodista.br/revistas/revistas-

unimep/index.php/impulso/article/view/579/1015. Acesso em: 2 jul. 2020.

Orcione Aparecida Vieira Pereira: Doutora em Ciências Sociais pela Universidade Federal de Juiz de Fora, professora de Educação Superior da Universidade do Estado de Minas Gerais.

Orcid: https://orcid.org/0000-0001-7961-0490

E-mail: orcionep@hotmail.com

Este periódico utiliza a licença Creative Commons Attribution 3.0, para periódicos de acesso aberto (Open Archives Iniciative - OAI). 